\title{
The Tobogan House: Revisiting the History
}

\author{
RAFAEL BENEYTEZ \\ Texas Tech University
}

As both a practitioners and an educators there is not a strong division between these two activities in our work. Our research is the foundation of our practice and vice-versa; our practice is a laboratory for our research. Teaching is a journey that involves the transition between both.

We would like to present this project as a conversation that juxtaposes several different canonical precedents. After guiding our students in the critical use of precedents through teaching, conversations, and discussions, we asked ourselves: "how many of the decisions made originated with voices that we admire from the past?" With this question in mind we realized, through a client's description of a commission for a private home, that several canonical projects could be directly referenced. We began the project by translating the client's spatial desires and descriptions with regard to a specific selection of precedents. We thought that later on we could modify them to transform our commission into a unique solution.

However, during the process we realized that the project was actually being made through the selection of the specific precedents. They began to provide a solution critically organized into a spatial framework that carefully addressed the client's list of needs and desires. Without mentioning the projects specifically, we found that the following works could truly represent the expectations of the client: the Morris Greenwald House, Connecticut, Mies van der Rohe 1956, Courtyard Houses (studies), Mies van der Rohe 1934-35, Villa Savoye, L'Corbusier, Poissy 1929, Case Study Houses, 194566, (figure 1) Maison a Bourdeaux, Koolhaas, 1998, (figure 2) Two-way Mirror Cylinder inside Cube, New York, 1991, Dan Graham, Chatsworth Greenhouse, Paxton, 1836 (figure 3).

The skin wraps the whole, gathering together this Atlas of canonical precedents while providing a unique lighting behavior that holds together a romantic narrative. This narrative stitches together relationships between past and present. The skin is designed as a membrane that is made of multiples layers and promote breathing instead of isolation, connection instead of division. It modulates the surrounding environment: sun radiation, the fluidity of light, and the impact of noise which comes primarily from the highway and a nearby school.

This project juxtaposes all of these matters together without a focused interest in form; it accepts the risk of the 'exquisite

\section{OPHELIA MANTZ}

Texas Tech University

corpse', heterogeneous conditions, and eclecticism that all together constitute our cultural logics and patterns. From the outside we could conceive of the project as a formal architecture, while, from the inside, the forms are dissolved without a center of gravity (figure 4).

A few other voices from the past such as Constant's 1957 work 'New Babylon', a project that emancipates life from the soil, and Sigfried Ebeling's 'Space as Membrane' from 1926 are present throughout. These work together to reinforce the deeper meanings of the house.

This paper aims to explain how the use of precedents in architecture might be instrumentalized when materializing a domestic space for a neophyte client. Regarding the specific case discussed here, the Tobogan House built by Z4Z4, while an architect's design tools might enhance the design project through studying history, the designer must be liberated from the objectification of architectural precedents. It may be possible to express this need by combining the inherited references of the past with the idea of agencement or disposition, rather than with the object itself. A bridge might be created between the idea of "Architecture as condition" and the mercantile and advertising world that represents desire through the object.

Those ideas are illustrated in the Tobogan House as a possible generative process. The project involves an inhabitant who is actually an active actor in the rhetoric of objects coming from the global market or, according to Guy Debord, part of the society of the spectacle ${ }^{1}$.

Today, facing the satisfaction linked to the hegemony of the object space that ensures wellbeing, maybe there is an opportunity for the architect to design a house thanks to a relational reading or "agencement" 2 , which means a spatial disposition that would be valued over the object itself. Therefore, an atmospheric reading of the precedents might be used to spatially elaborate the construction to the client's desire. The precedent might become a medium to identify and to analyze the specific underlying desires that drive the domestic space's construction.

The idea of linking a desire to an iconic precedent should accept the concept of multiplicity. In other words, instead of fragmenting the desire, the construction of heterogeneity should be legitimized. However, a house is the image of 


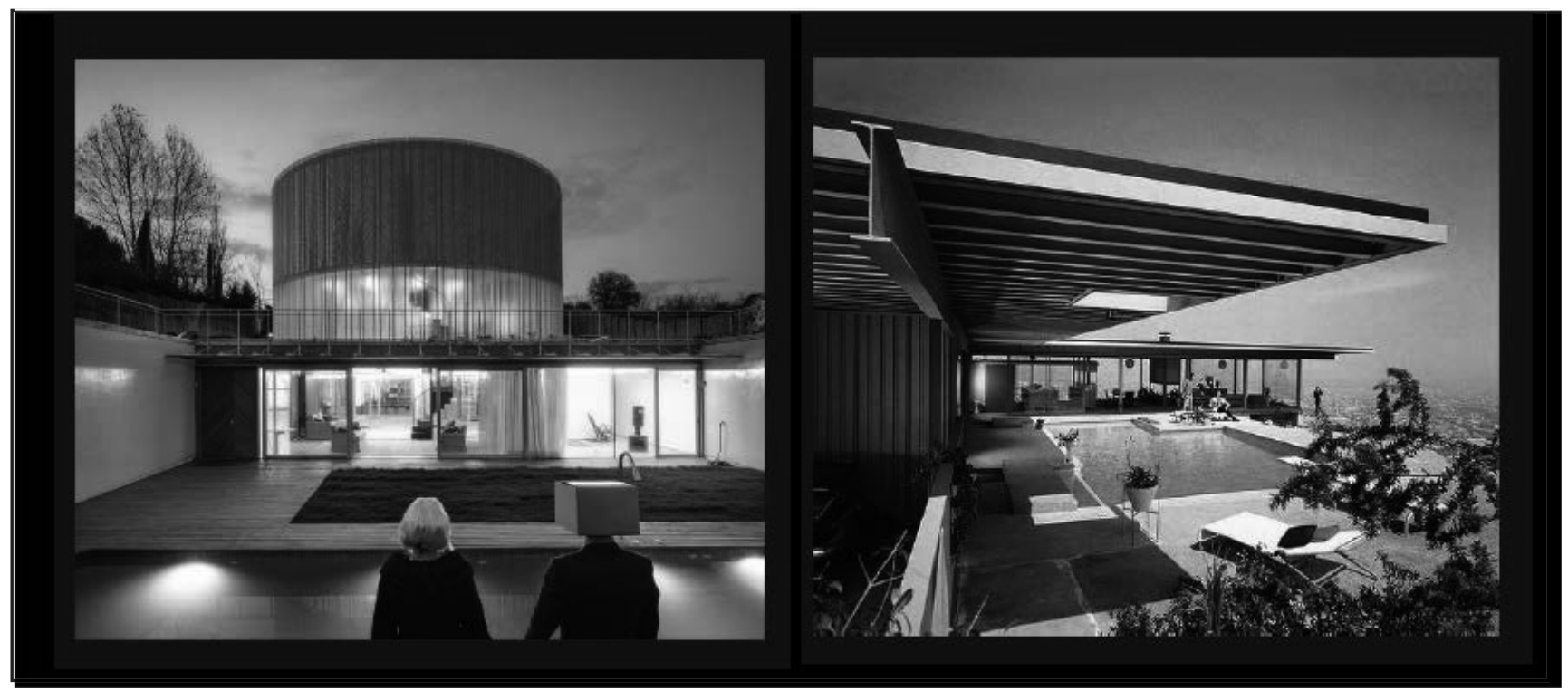

Figure 1: Extracted from the visual presentation at ACSA conference. On the right, The Stahl House, case study House 22 by P. Koeing, 1959 , Los Angeles. On the left, Tobogan House, Madrid, Spain, 2016

everyday life, and the home space is loaded with images resulting from layers of time and culture that resonate the mundane and the epic. According to Henri Lefebvre, decoding everyday life allows for deciphering contemporary society.

Desire might be considered the underlying structure element that dictates to man how to dwell between earth and heaven. The construction of desire navigates between reality and imagination. However, at the same time, desire may be the generator of a relational space or a social interstice, a space of exchange that escapes, according to Karl Marx, to the economic frame. It is a space for human relations, for the experience or the collective elaboration of meaning ${ }^{3}$.

But how to analyze the construction of desire? How to decipher it and therefore translate it into spatial terms? Desire is a cultural construction that organizes the domestic space in our daily lives. The world of desire is a dream inscribed in the day-by-day, as introduced by Henri Lefebvre in The Critique of Everyday Life ${ }^{4}$.

This paper would like to emphasize the idea that the projection of modern life's domestic space is essentially related to the dissection of desire. The domestic space builds one's privacy. It is a multiple cultural result that travels from monotony to the fascination of the everyday marked by spectacle.

In 1967, Guy Debord explained in The Society of the Spectacle that "The whole life of those societies in which modern conditions of production prevail presents itself as an immense accumulation of spectacles. All that once was directly lived has become mere representation."
The Tobogan House would like to speculate on a specific modus operendi on the use of precedents, as it might be considered a new instrumentality that recognizes the past as it is today. At the same time, the mechanisms used to construct the desires that build domestic spaces have been directly influenced by relevant authors who specialized in analyzing modern society, such as Guy Debord, Henri Lefebvre, Gilles Deleuze and Félix Guattari, Nicolas Bourriaud, and Keller Easterling.

The project is a conversation that juxtaposes different canonical precedents to match the Tobogan House client's desires.

The idea of desire has played an important role in the development of this project. The house assumes the heterogeneity and the multiplicity of desire. Thus, the Tobogan House should be considered an agencement or disposition of different fragments of canonical architectural works, specifically precedents within modernity that form a generic image that still lives in collective memories.

The project started by translating the client's spatial desires and descriptions in correspondence with specifically selected precedents.

\section{THE DESIRE AS A MULTIPLICITY}

What is a multiplicity? According to the philosopher Gilles Deleuze, a multiplicity " [...] is, in the most basic sense, a complex structure that does not reference a prior unity. Multiplicities are not parts of a greater whole that have been fragmented, and they cannot be considered manifold expressions of a single concept or transcendent unity." The client's desires were fragments whose sole relationship was sheer difference ${ }^{5}$. 


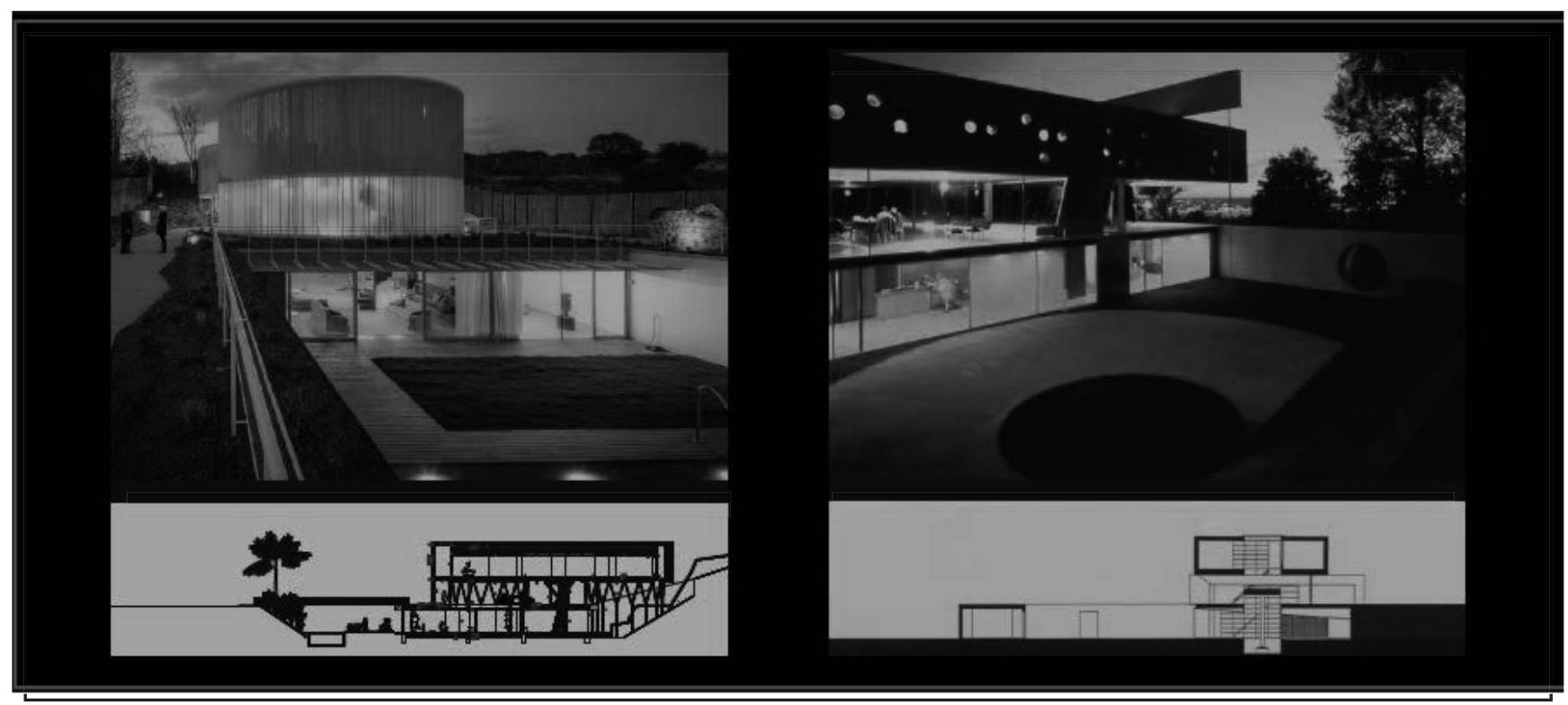

Figure 2: Extracted from the visual presentation at ACSA conference, on the right La Maison de Bordeaux, Rem Koolhaas, France, 1998.. On the left, Tobogan House, 2016

First, she had the desire to live in a pragmatic and modern house. Her desire came the Morris Greenwald House in Connecticut built by Mies van der Rohe in 1956. The representation of a generic modern space can be found in the Greenwald House. The T-shaped element that organizes the house's rooms and circulation is borrowed from this precedent and generates the program in each floor.

Second, she expressed her desire to live in nature within the interior of the house, much like the Courtyard Houses (studies) built by Mies van der Rohe in 1934-35. This precedent represents the idea of a courtyard inside the house to achieve the spatial expansion of the interior. However, the decision to bury the living floor does not aim to reproduce or reuse in an identical way this masterpiece of architecture but to use a specific spatial agencement or disposition independent from Mies Van Der Rohe's syntax.

Third, the desire to use the car to circulate around and below the house came from the Villa Savoye by Le Corbusier in Poissy 1929. The emancipation of the house from the ground floor celebrates one of the most important technical solutions developed during the first half of the 20th century. However, the lift is the most important spatial relation that was reused. The structural system to reach this goal is a pure product of an industrial steel structure that ignores the construction in the site, as was the case for the concrete pillars developed by Le Corbusier. The car circulates around the first cylinder and below the house. The middle plan is dissolved, even erased from view.

The client's fourth desire was based on emphasizing everyday life and hedonism. This idea came from the Case Study
Houses, 1945-66. The relation between program and hedonism is dominant, and the program should be illustrated within its extension to the exterior or hybrid spaces. The articulation of other symbolic representations was avoided. Once privacy has been constructed, the program unfolds without limitations of visual relationships to show the pleasure of everyday life.

Her fifth desire expressed her aspiration to live in extremely different types of spaces, ambiences, and organizations, much like the Maison de Bordeaux by Rem Koolhaas in 1998. The vertical juxtaposition offers vastly different spatial features. The house is a contrast between the solidity of concrete volumes attached to the ground and the steel cylinders playing with dematerialization.

Her sixth desire was to have transparency and intimacy at the same time. This spatial relationship came from the TwoWay Mirror Cylinder Inside Cube by Dan Graham in New York, 1991. The house's ambiguity appears through multiple transparent effects and mirrored surfaces.

The seventh desire was shaped from the idea to have ambiguous experiences in the house through lightness and green plants in the interior. This idea resonated with the Chatsworth Greenhouse by Joseph Paxton in 1836.

The glaze effect of light created by the use of a specific type of glass and the reflection of light through different floors, wall surfaces, and materials produce multiple sunray directions, constructing the house's atmosphere. 


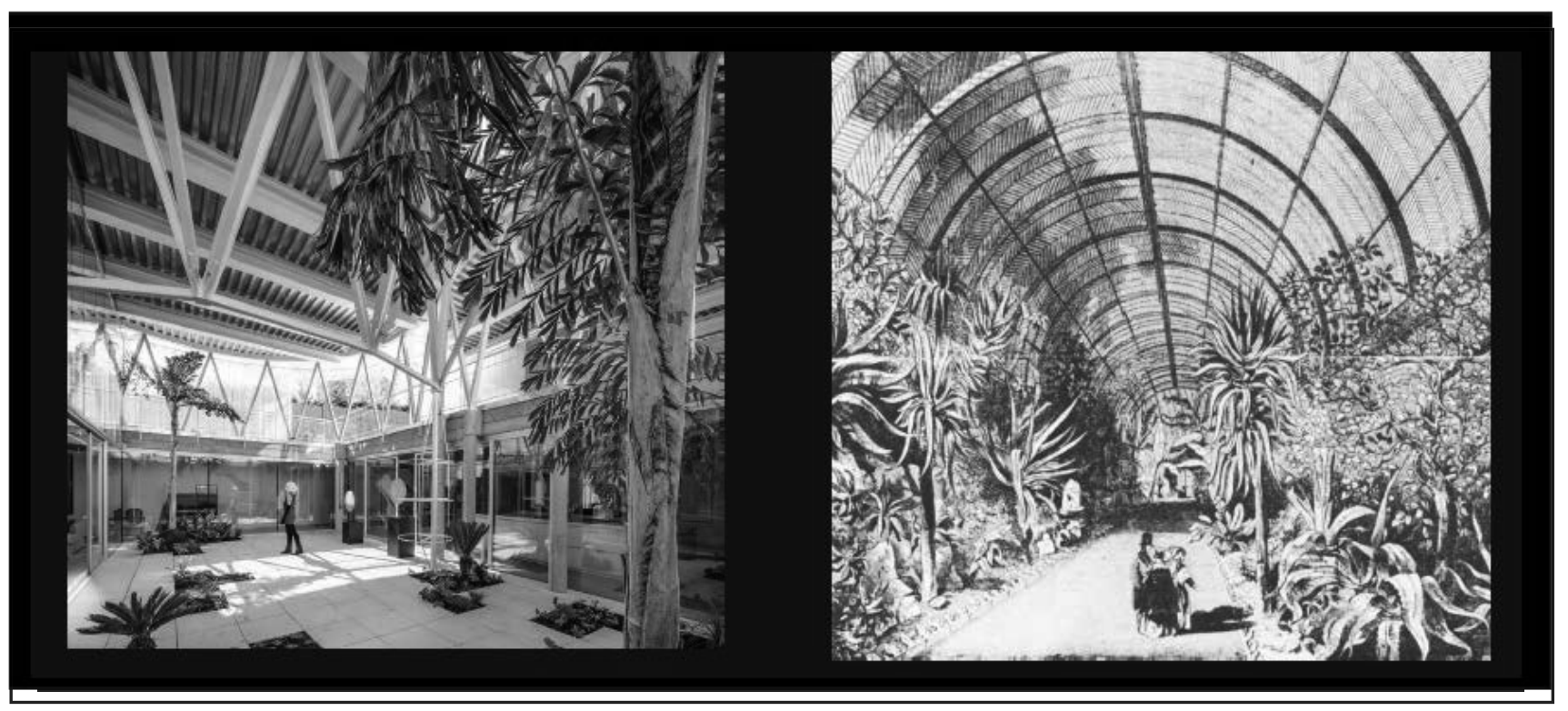

Figure 3: Extracted from the visual presentation at ACSA conference. On the right, Chatsworth Greenhouse by Joseph Paxton in 1836. On the left, The Tobogan House by Z4A, Madrid, Spain, 2016.

An atmosphere is made by the skin. The skin modulates the multiplicity, the potentialities, the forces of the client's desires and environmental energies. The skin enhances the relations between the fragments of canonical precedents, while providing a unique light behavior that holds together a romantic narrative. These narratives stitch together relationships between past and present, language and technical solutions, desire and atmosphere. The skin is designed as a membrane made from multiple layers and promotes breathing instead of isolation, connection instead of division. The skin modulates the surrounding environment composed of sun radiation, the fluidity of light, and the impact of noise coming from the highway and a nearby school.

This project juxtaposes all of these matters together without a focused interest in form; instead, it is a space of fragments, whose sole relationship is sheer difference. It is more a "reembody," or from Deleuze's perspective, un corps sans organe $^{6}$, where there is no interest to connect the whole with the parts. It assumes the risk of the cadavre exquis, or "exquisite corpse;" heterogeneous conditions and eclecticism all together constitute our cultural logics and patterns.

\section{ATMOSPHERICAL PRECEDENTS}

The paradigmatic houses chosen from the 20th century materialized the multiplicity of the client's desire to recognize our heritage across different time periods. Considering this legacy from Le Corbusier, Mies Van Der Rohe, or Rem Koolhass serves as a reminder of the process and the time needed for society to establish a collective memory and thus construct our culture. The elements that underlie a culture and therefore influence the construction of our desires represent a powerful tool that might be reinforced in an architect's education.
While the reinterpretation of these architectural masterpieces is not intended to be a copy-paste of the physical elements that make up these buildings, which would reduce the project to a mere catalog of objects, it does manifest the need to use the relational components of the spaces within the precedents. In other words, the reuse of history aims to be, in this case, exclusively an atmospheric consideration of the spaces.

From the outside, one might consider the project from an absolute formal position. The semantic fake, in this case, is absolute. Otherwise, the apparently pure objectual container, generated from the use of primary geometrical shapes, offers interior spaces where the forms are dissolved without a center of gravity.

\section{CONCLUSION}

The work developed in the Tobogan House might be an opportunity to use the contemporary discourse coming from the art world to renounce the architectural approach of objectivization. The cultural patterns in which we live today seem to promote the need to consider the interstitial space that starts from the intersubjectivity, the atmospheric construction of space, a space constituted from experience. Given the insatiability of the object's society, the paper would like to propose revisiting history from a purely atmospheric reading.

The Tobogan House, developed between academia and practice, tries to place architecture in a non-formal space. Currently, to approach architectural matters, this paper's methodology is based on considering different concepts as multiplicities and potentialities to promote continuity instead of fracture. 


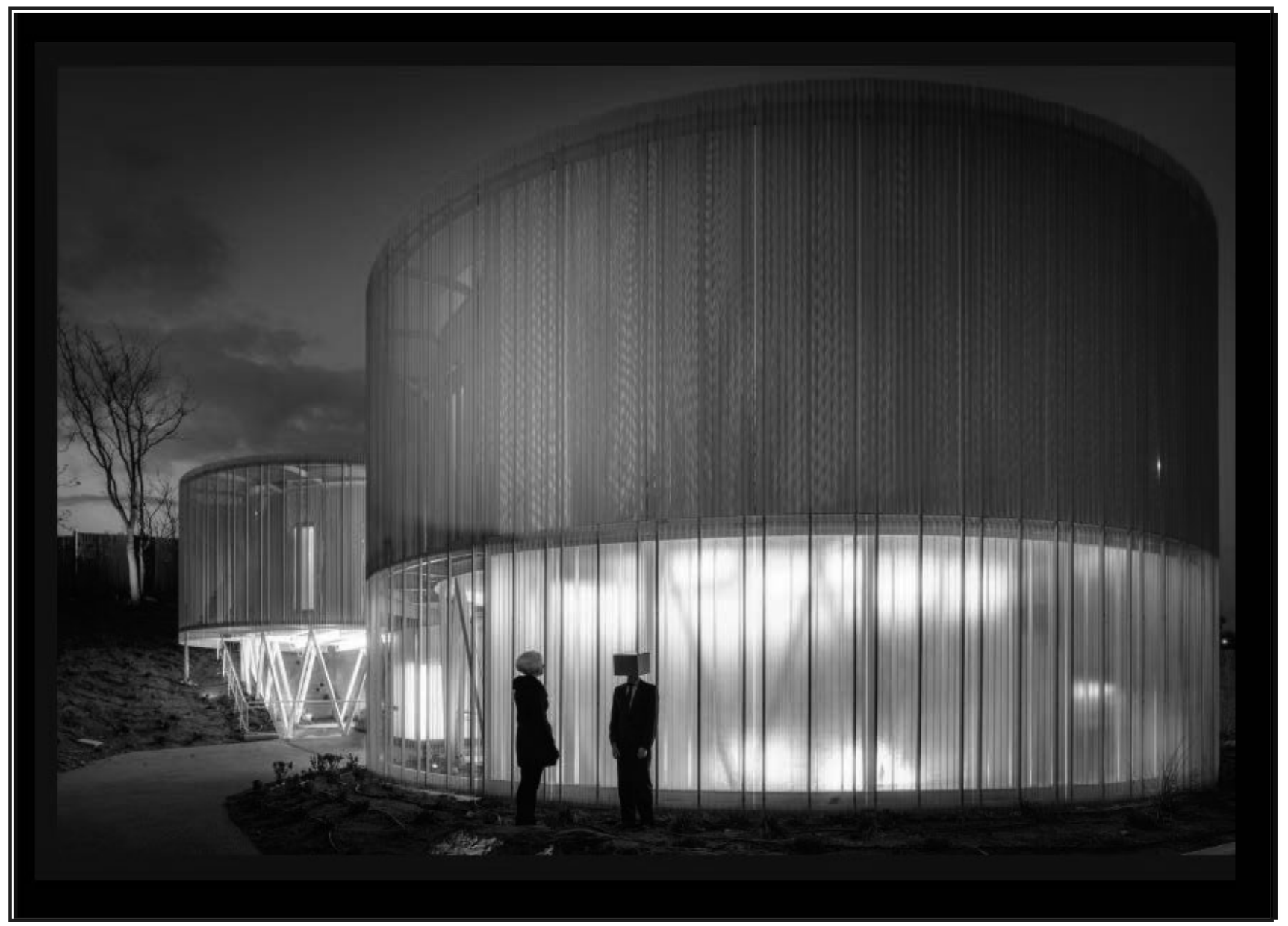

Figure 4: The Tobogan House, Madrid, Spain, 2016, Z4A, Photo by Imagen Subliminal

\section{ENDNOTES}

1. Debord Guy, The Society of the Spectacle, traslation by Fredy Perlman and Jon Supak, Black and Red, 1970. First edition in french 1967, Buchet-Chastel.

2. Easterling Keller, Extrastate Craft, The Power of Infrastructure Space, Verso Books, 2016.

3. Bourriaud Nicolas, l'Esthetique Relationnelle, Les Presses du Reel, 1998. p.15.

4. Lefbvre, Henri, The critique of everydaylife, Editions Gallimard, 1968. p.140.

5. Deleuze Gilles and Guattari Felix, Anti-Oeudipus: Capitalism and Schizophrenia, translated by Robert Hurley, Mark Seem and Helen R. Lane, Viking Penguin, 1977.

6. Deleuze Gilles and Guattari Felix, A thousand Plateaus, University Of Minnesota Press, 1987. p.187-204. 